\title{
A Study on the Impact of Pandemic COVID-19 on Global Economy - A Questionnaire Based Study
}

\section{Monesh Babu J. D. ${ }^{1}$, Preetha S', Dinesh Premavathy ${ }^{3}$, Lavanya Prathap ${ }^{4}$}

Section: Healthcare

Sci. Journal Impact

Factor: 6.1 (2018)

ICV: 90.90 (2018)

(c) (i) (8)

Copyright@IJCRR
'Saveetha Dental College and Hospitals, Saveetha Institute of Medical and Technical Sciences (SIMATS), Saveetha University, Chennai, India; ${ }^{2}$ Senior Lecturer, Department of Physiology, Saveetha Dental College and Hospitals, Saveetha Institute of Medical and Technical Sciences (SIMATS), Saveetha University, Chennai, India; ' 3 Senior Lecturer, Department of Anatomy, Saveetha Dental College and Hospitals, Saveetha Institute of Medical and Technical Science (SIMATS), Saveetha University, Chennai, India; ${ }^{4}$ Assistant Professor, Department of Anatomy, Saveetha Dental College and Hospitals, Saveetha Institute of Medical and Technical Sciences (SIMATS), Saveetha University, Chennai, India.

\section{ABSTRACT}

Introduction: Coronavirus disease (COVID-19) is an infectious disease caused by a coronavirus. The spread of COVID-19 could be controlled through social distancing which has resulted in the shutdown of financial markets, business, corporate offices, transports across the countries, and other activities. Many experts on economic and financial matters have warned about the worsening condition of global economic and financial structure. Covid-19 is harming the global economy because the world has been experiencing the most difficult economic situation. The aim of the present study is to assess the impact of pandemic COVID-19 on the global economy.

Materials and Methods: The study was conducted with a study population of 136 subjects. A self-administered questionnaire was distributed to the study population through online survey links and the data were collected, tabulated, and statistically analyzed using SPSS software.

Result: The results revealed that 93.33 percent of the study participants were aware of the impact of pandemic COVID-19 on the global economy.

Conclusion: The impact of pandemic COVID-19 led to the fatal global recession.

Key Words: Coronavirus, Pandemic, Impact, Global economy, Recession, Finance

\section{INTRODUCTION}

The outbreak of pandemic COVID-19 all over the world has distributed the political, social, economic, religious, and financial structures of the world. COVID-19 affected day to day life slowing down the global economy, due to this pandemic thousands of people who are being sick are being killed. Symptoms of this pandemic COVID-19 Include fever, common cold cough, breathing problems ultimately leading to pneumonia for this pandemic the vaccines are not yet found or not yet available ${ }^{1}$. The initiative of taking extensive precautions like extensive hygiene protocol for example washing your hands regularly comes in avoidance of face-to-face interactions, social distancing Wearing masks. Several authors have also studied and given a brief overview on the impact of pandemic COVID-19 affecting the global economy ${ }^{2}$. The outbreak of pandemic Covid-19 everywhere the planet has disturbed the political, social, eco- nomic, religious, and financial structures of the entire world. The world's topmost economies such as the US, China, UK, Germany, France, Italy, Japan, and many others are on the verge of collapse. Many experts on economic and financial matters have warned about the worsening condition of global economic and financial structure. COVID-19 is harming the global economy because the world has been experiencing the most difficult economic situation.

The spread of COVID-19 could be controlled through social distancing which has resulted in the shutdown of financial markets, business, economic activities, government offices, corporate offices like international exports and imports increased number of lockdown days, monetary policy decisions, travel restrictions across countries had really brought down the level of economic activities. Also restriction imposed on internal movement had surely affected economy ${ }^{3-8}$. Evidence from ${ }^{9}$ China-increases commodities and age, with

\section{Corresponding Author:}

Preetha S, Senior Lecturer, Department of Physiology, Saveetha Dental College and Hospitals, Saveetha Institute of Medical and Technical Sciences (SIMATS), Saveetha University, Chennai, 162, Poonamallee High Road Chennai, India; Mob: 8608566435; Email: preethas.sdc@ saveetha.com

ISSN: 2231-2196 (Print)

Received: 25.07 .2020
ISSN: $0975-5241$ (Online)

Revised: 18.08 .2020
Accepted: 26.09 .2020
Published: 20.10 .2020 
exceptionally high rates $(>14 \%)$ Among adults aged at least eight years ${ }^{10,11}$. COVID-19, a severe health problem affected the global economy interconnected to the world.

The COVID-19 outbreak has greatly affected the air travel industry. The International Air Transportation Association (IATA) has declared that the air travel industry would be losing around US\$ 113 billion as a result of COVID-19 outbreak ${ }^{6}$. Coronavirus outbreak had led the government to the suspension of tourism and tourist people and such restrictions would result in loss of great revenue to the country. The tourism industry alone would lose around \$200 billion globally, excluding other loss of revenue for tourism travel, and it was forecasted that the aviation industry would lose a total loss of $\$ 113$ billion according to IATA ${ }^{12,13}$. The coronavirus pandemic is immeasurable and therefore all countries need to work together with cooperation and coordination to protect human beings as well as limit the economic damages.

Previous studies have been done by our team on various aspects that include online surveys studies ${ }^{14}$, like neonatal jaundice ${ }^{15}$, muscular endurance ${ }^{16}$, physical fitness ${ }^{17}$, tongue exercise ${ }^{18}$, expiratory flow rate ${ }^{19}$, nasal spirometry ${ }^{20}$, survey on onychocryptosis ${ }^{21}$, infertility caused due to obesity ${ }^{22-24}$, treatment for asthma ${ }^{25}$, and acupuncture ${ }^{26}$ all the experience led us to work on the current topic. The aim of the present study is to analyze the impact of pandemic COVID-19 on the global economy.

\section{MATERIALS AND METHOD}

The present study was carried out among 136 subjects from the general population. A cross-sectional study conducted with a self-administered questionnaire was designed based on the impact of COVID-19 on the global economy. The questionnaire was distributed through online (https://docs. google.com/forms/d/e/1FAIpQLSeD6znx0Ht9El7iIKARN 9SjcO0xrcmRxgpYyeYKR647YxDb2g/viewform?usp=sf link) Survey. The questionnaire consisted of 15 questions that gave more attention to the impact of pandemic COVID-19 on the global economy, global economic recession, and the strategies to overcome this impact.

\section{Statistical Analysis}

The data were collected and analyzed using SPSS software. Chi-square test was analyzed to study the association between gender and awareness on the impact of COVID-19 on the global economy and the results were represented in the form of bar charts.

\section{RESULTS AND DISCUSSION}

In the present study $54.81 \%$ were males and $45.18 \%$ were females [Figure 1]. About 22.96 percent of the participants felt by using masks, $22.22 \%$ Social distancing, $8.89 \%$ good proper hygiene practices and $45.93 \%$ responded to all the above to minimize the risk factors on the spread of COVID-19 in the urban environment [Figure 2]. About $83 \%$ of the participants were aware of our present global economic crisis and a minority of $17 \%$ of the respondents was not aware of the present global economic crisis [Figure 3]. About $80 \%$ of the study population thinks WHO plays crucial role to reduce the global economic recession due to the pandemic COVID-19 effect and 20\% answered no [Figure 4]. The majority of $51.11 \%$ respondents felt that globalization will be affected for a long period of time due to the Pandemic COVID-19 minority of 42.96 percent felt it will last for some short span of time period [Figure 5]. Majority of the respondents 93.33 percent felt that this survey was really useful and due to this the way they gained some adequate knowledge on the impact of pandemic COVID-19 on the global economy [Figure 6]. $79.41 \%$ were aware of the impact of COVID-19 outbreak affecting oil-dependent countries and $20.59 \%$ were not aware [Figure 7]. About $33.09 \%$ were aware of COVID-19 crises on import and export of goods between countries [Figure 8]. $61.76 \%$ were aware of the impact of COVID-19 outbreak affecting the travel industry [Figure 9]. 63.24\% were aware that COVID-19 outbreak had affected agricultural activities [Figure 10]. 95.59\% were aware of the Pandemic COVID-19 impact on the stock market [Figure 11]. Males were much aware that the outcome of COVID-19 outbreak affecting the financial stock P-value - $0.765(>0.05)$ - statistically not significant [Figure 12]. Males had better knowledge on COVID-19 affecting corporate companies P-value $0.017(>0.05)$ - and it was statistically significant. [Figure13]. Males had better knowledge than females on COVID-19 outbreak had affected banking P-value - $0.704(>0.05)$ - and it was found to be statistically not significant [Figure 14]. Males had better knowledge of COVID-19 affecting corporate companies P-value $-0.945(>0.05)$ which is statistically not significant [Figure 15].

The number of lockdown days significantly increased affecting the closing, opening lowest, and highest stock prices and the level of general economic activities imposed restriction movements also had a positive effect on the level of economic activities and the closing, opening, lowest, and highest stock prices. 80.7 percentage of respondents were aware of the global economic recession and other authors studied the coronavirus outbreak and spillover of COVID-19 and global economy ${ }^{27}$.

The restriction imposed on various activities would lower the economic activities creating jobless situations for many people ${ }^{28}$. According to the study by Ozili, 2020, the author has stated that the COVID-19 outbreak would affect importdependent countries very badly ${ }^{13}$. This is similar to the present study which has stated that the study population had awareness COVID-19 having a great impact on the global 
economy in imports and exports. The present study has also identified the awareness of COVID-19 impact on oil-dependent countries. This study studied the global economic recession of 2020 in relation to the global economy ${ }^{29} .51 .5$ percent of the respondents believe measures will be taken to stop this economic recession, Other study states that appropriate policy will be taken by the government to sustain economic growth ${ }^{30}$. The majority of 50.4 percent of the respondents felt the impact of globalization would be for a longer period.

Another study states ${ }^{20}$ that it is evident that the global economy is grinding interest rates that drop sharply; the labor cost production becomes less important ${ }^{14}$. The present study has some limitations that the questionnaire was distributed to a limited number of people through the survey, the survey could be conducted large-scale to create maximum awareness and to gain more knowledge among the study population the sample size of the survey was moderate.

\section{CONCLUSION}

In the present study, it was evident that most of the respondents were aware of the impact of pandemic COVID-19 on the global economy. Men (52\%) are more concerned about the impact of COVID on the economy than women (42\%). However, the difference is more distinct with regard to corporate jobs where men are twice as concerned as women. Many experts on economic and financial matters have warned about the worsening condition of global economic and financial structure.

\section{REFERENCES}

1. Paramasivam A, Priyadharsini JV, Raghunandhakumar S, Elumalai P. A novel COVID-19 and its effects on cardiovascular disease. Hypertens Res. 2020 Jul;43(7):729-30.

2. Meng L, Hua F, Bian Z. Coronavirus disease 2019 (COVID-19): emerging and future challenges for dental and oral medicine. J Dent Res [Internet]. 2020; Available from: https://journals.sagepub.com/doi/abs/10.1177/0022034520914246

3. Lakner C, Prydz EB, Soler Lopez J, Wu R, Zhao Q. Estimating Global Poverty in Stata: The Povcalnet Command. 2019; Available from: https://elibrary.worldbank.org/doi/pdf/10.1596/32477

4. Gilbert M, Pullano G, Pinotti F, Valdano E, Poletto C, Boëlle $\mathrm{P}-\mathrm{Y}$, et al. Preparedness and vulnerability of African countries against importations of COVID-19: a modelling study. Lancet. 2020 Mar 14;395(10227):871-7.

5. Allen F, Carletti E. An Overview of the Crisis: Causes, Consequences, and Solutions. International Review of Finance. 2010 Mar;10(1):1-26.

6. Bagliano FC, Morana C. The Great Recession: US dynamics and spillovers to the world economy [Internet]. Vol. 36, Journal of Banking \& Finance. 2012. p. 1-13. Available from: http:// dx.doi.org/10.1016/j.jbankfin.2011.06.002

7. Bezemer DJ. The Credit Crisis and Recession as a Paradigm Test. J Econ Issues. 2011 Mar 1;45(1):1-18.

8. Cooper RN, Koo RC. Balance Sheet Recession: Japan's Strug- gle with Uncharted Economics and Its Global Implications [Internet]. Vol. 83, Foreign Affairs. 2004. p. 158. Available from: http://dx.doi.org/10.2307/20033915

9. Fathima F, Preetha P. Evaluation Of Thyroid Function Test In Obese Patients. Asian Journal of Pharmaceutical and Clinical Research. 2016 Dec 1;353-5.

10. Times F. Global recession already here, say top economists. Financial Times Retrieved from https:/www ft com/content/ be732afe-6526-11ea-a6cd-df28cc3c6a68 Accessed. 2020;24.

11. Cochrane JH. Understanding policy in the great recession: Some unpleasant fiscal arithmetic. Eur Econ Rev. 2011 Jan 1;55(1):230 .

12. Ilankizhai RJ, Devi G. Role of environmental factors on sleep patterns of different age groups: A survey-based study. Asian J Pharm Clin Res. 2016;9:124-6.

13. Ozili PK, Arun T. Spillover of COVID-19: Impact on the Global Economy [Internet]. SSRN Electronic Journal. Available from: http://dx.doi.org/10.2139/ssrn.3562570

14. Samuel AR, Devi MG. Geographical distribution and occurrence of Endemic Goitre. J Pharm Technol [Internet]. 2015; Available from: http://www.indianjournals.com/ijor.aspx?target $=$ ijor:rjpt $\&$ volume $=8 \&$ issue $=8 \&$ article $=001$

15. Harsha L, Priya J, Shah KK, Reshmi B. Systemic Approach to Management of Neonatal Jaundice and Prevention of Kernicterus [Internet]. Vol. 8, Research Journal of Pharmacy and Technology. 2015. p. 1087. Available from: http://dx.doi. org/10.5958/0974-360x.2015.00189.4

16. Abigail, Priya J, Devi G. Evaluation of Muscular Endurance among Dentists. Ind Jour of Publ Health Rese \& Develop. 2019;10(10):258.

17. Priya AJ, Devi G, Others. Physical Fitness among the Dental Physician, Dental Undergraduates and Postgraduates Students. Indian Journal of Public Health Research \& Development. 2019;10(10):223-6.

18. Shruthi M, Preetha S. Effect of Simple Tongue Exercises in Habitual Snorers. Research Journal of Pharmacy and Technology. 2018;11(8):3614-6.

19. Timothy CN, Devi RG, Priya AJ. Evaluation of Peak Expiratory Flow Rate (PEFR) in Pet Owners. Indian Journal of Public Health Research \& Development. 2019;10(8):803-6.

20. R GD, Sethu G. Evaluation Of Adenoids By Oronasal And Nasal Spirometry [Internet]. Vol. 11, Asian Journal of Pharmaceutical and Clinical Research. 2018. p. 272. Available from: http:// dx.doi.org/10.22159/ajpcr.2018.v11i10.27365

21. Iyer PK, Devi RG, Priya AJ. A Survey Study on Causes, Treatment and Prevention of Onychocryptosis. Indian Journal of Public Health Research \& Development. 2019;10(8):807-11.

22. Baheerati MM, Gayatri Devi R. Obesity in relation to Infertility [Internet]. Vol. 11, Research Journal of Pharmacy and Technology. 2018. p. 3183. Available from: http://dx.doi. org/10.5958/0974-360x.2018.00585.1

23. Choudhari S, Jothipriya MA. Non-alcoholic fatty liver disease [Internet]. Vol. 9, Research Journal of Pharmacy and Technology. 2016. p. 1782. Available from: http://dx.doi.org/10.5958/0974360x.2016.00360.7

24. Renuka S, Sethu G. Regeneration after Myocardial Infarction [Internet]. Vol. 8, Research Journal of Pharmacy and Technology. 2015. p. 738. Available from: http://dx.doi.org/10.5958/0974360x.2015.00117.1

25. Dave PH, Preetha. Pathogenesis and Novel Drug for Treatment of Asthma-A Review [Internet]. Vol. 9, Research Journal of Pharmacy and Technology. 2016. p. 1519. Available from: http:// dx.doi.org/10.5958/0974-360x.2016.00297.3

26. Swathy S, Gowri Sethu V. Acupuncture and lower back pain [In- 
ternet]. Vol. 8, Research Journal of Pharmacy and Technology. 2015. p. 991. Available from: http://dx.doi.org/10.5958/0974360x.2015.00165.1

27. Georgieva K, Malpass D. Joint Press Conference on COVID-19 by IMF Managing Director and World Bank Group President [Internet]. 2020. Available from: http://dx.doi.org/10.1596/33488

28. Bentolila S, Jansen M, Jiménez G. When Credit Dries Up: Job Losses in the Great Recession [Internet]. Vol. 16, Journal of the European Economic Association. 2018. p. 650-95. Available from: http://dx.doi.org/10.1093/jeea/jvx021

29. Horowit J. The global coronavirus recession is beginning. CNN. Media report. 2020.

30. Jagannathan R, Kapoor M, Schaumburg E. Causes of the great recession of 2007-2009: The financial crisis was the symptom not them disease! Journal of Financial Intermediation. 2013 Jan $1 ; 22(1): 4-29$.

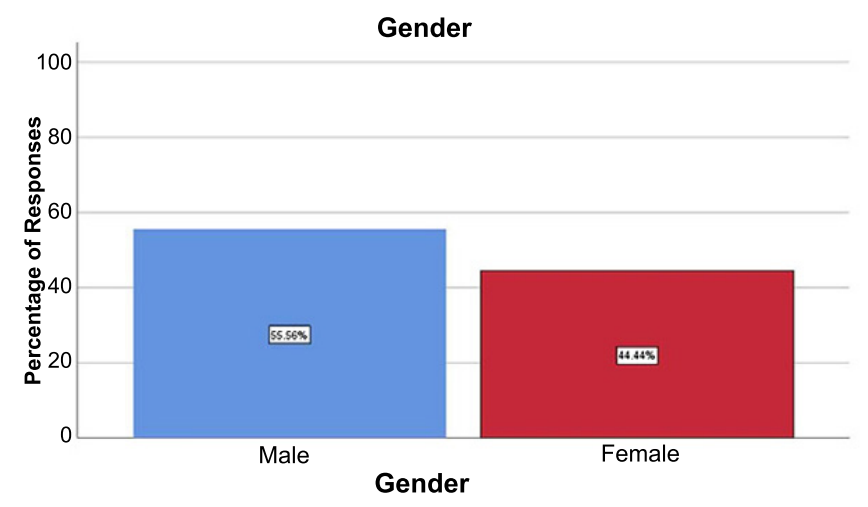

Figure 1: Bar graph representing the percentage distribution of gender of the participants. X-axis represents the responses and $\mathrm{Y}$-axis represents the percentage of responses. $55.9 \%$ were males and $44.1 \%$ were females where blue color denotes male and red color denotes female.

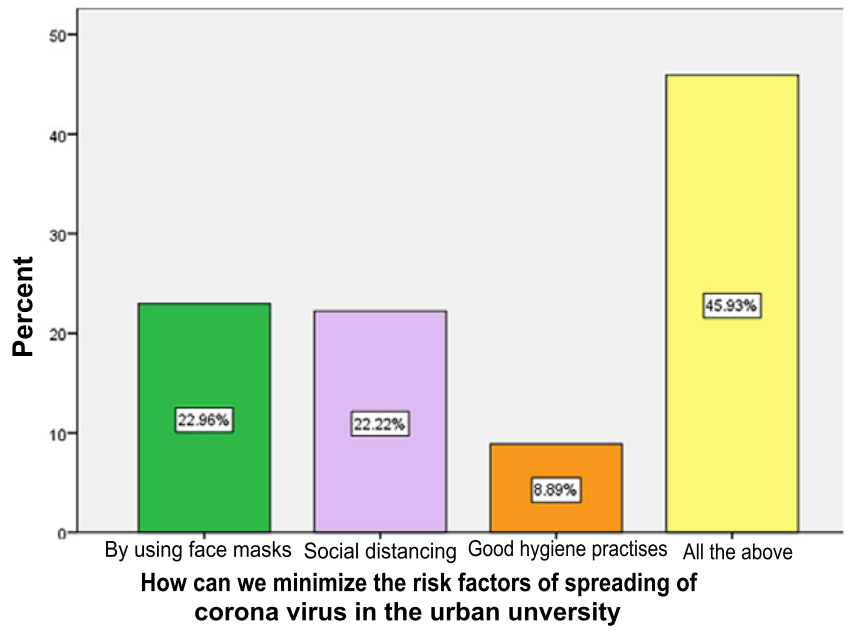

Figure 2: Bar graph representing the percentage distribution on the ways to minimize the risk factor of the spreading of coronavirus in the urban environment. $\mathrm{X}$-axis represents the re-

\section{QUESTIONNAIRE}

1. Gender distribution

2. Steps to minimize the risk factors of spreading of coronavirus in the urban universities

3. Awareness of present global economic crisis

4. Role of WHO in pandemic covid 19

5. Does the rapid spread of covid 19 mark the end of globalisation

6. Impact of covid 19 outbreak affecting oil dependent countries

7. Covid 19 output crisis on imports and exports of essential goods

8. Impact of covid 19 crisis on affecting the travel industry

9. Impact of covid 19 on agricultural activities

10. Impact of covid 19 on financial stock markets

sponses and $\mathrm{Y}$-axis represents the percentage of responses. Where green color denotes 22.96 percent of the respondents felt by using masks, pink color denotes $22.22 \%$ Social distancing, orange color denotes $8.89 \%$ good proper hygiene practices and yellow color denotes $45.93 \%$ responded to all the above to minimize the risk factors on the spread of COVID-19 in the urban environment.

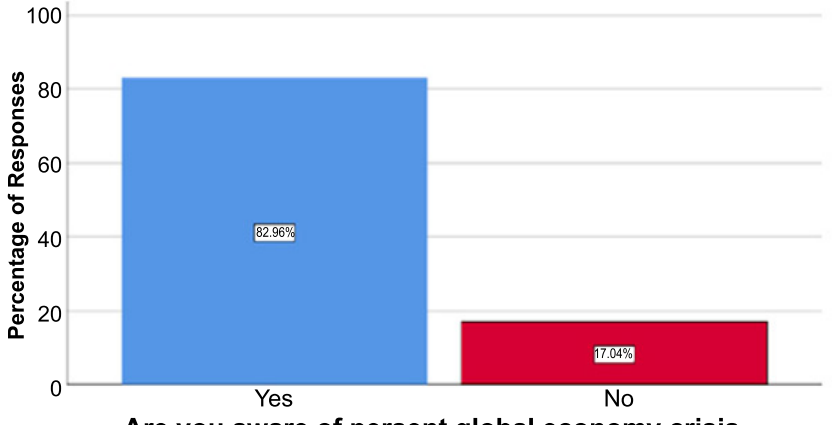

Are you aware of persent global economy crisis

Figure 3: Bar graph representing the percentage distribution of awareness of the present global economic crisis. X-axis represents the responses and $\mathrm{Y}$-axis represents the percentage of responses where blue color denotes Yes and red color No. $83 \%$ of the respondents were aware and $17 \%$ of the respondents were not aware of the present global economic crisis. 


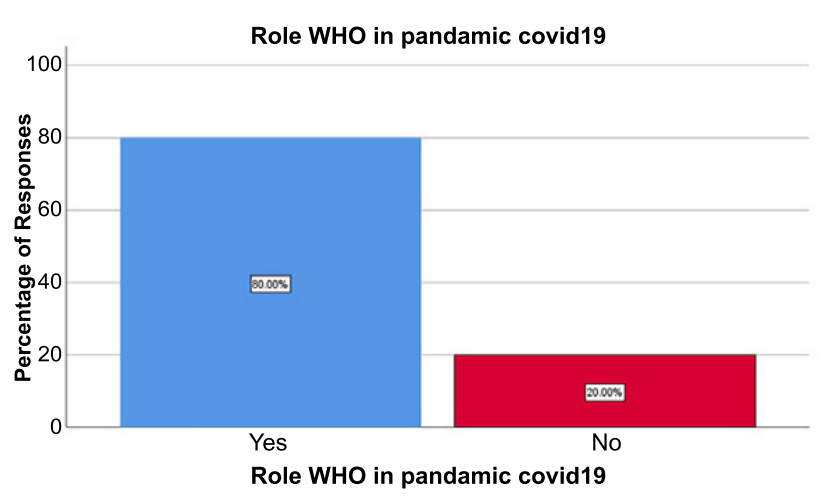

Figure 4: Bar graph representing percentage distribution of Knowledge on the crucial role of $\mathrm{WHO}$ to reduce the global economic recession due to the pandemic COVID-19 effect. Xaxis represents the responses and $Y$-axis represents the percentage of responses where blue color denotes Yes and red color denotes No. $80 \%$ percent of the study population thinks WHO plays the crucial role, $20 \%$ answered No.

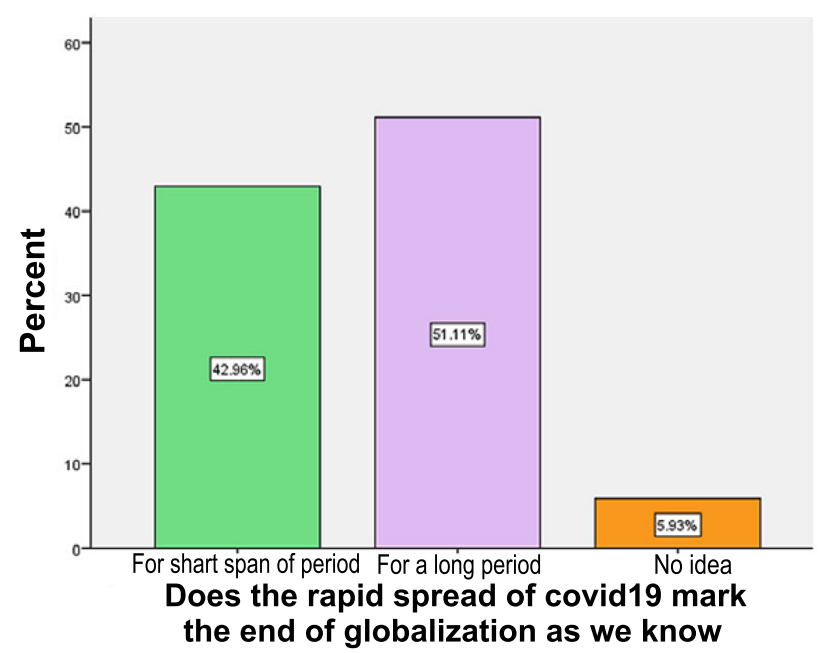

Figure 5: Bar graph representing the percentage distribution of awareness of the rapid spread of COVID-19 marks the end of globalization. X-axis represents the responses and Y-axis represents the percentage of responses where Pink color denotes $51.11 \%$ respondents felt that the globalization will be affected for a long period of time due to the Pandemic COVID-19, green color denotes 42.96 percentage felt, it will last for some short span of the time period.

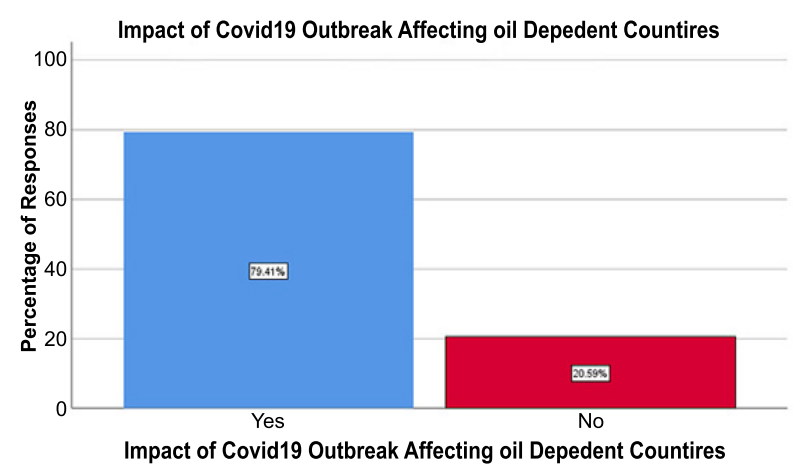

Figure 6: Bar graph representing the percentage distribution of awareness of the impact of the COVID-19 outbreak affecting oil-dependent countries. X-axis represents the responses and Y-axis represents the percentage of responses. Where Blue color denotes yes and red color denotes no.79.41\% answered yes, $20.59 \%$ answered no.

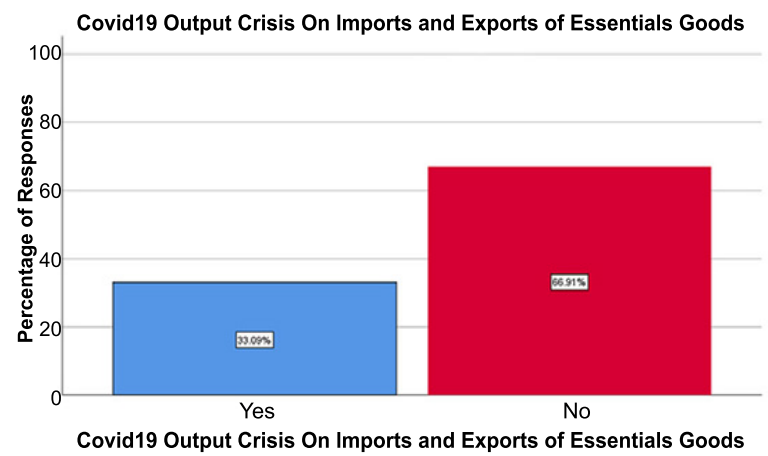

Figure 7: Bar graph representing the percentage distribution of awareness of the COVID-19 crisis on import and export of goods between countries. $\mathrm{X}$-axis represents the responses and $\mathrm{Y}$-axis represents the percentage of responses where Blue color denotes Yes and red color denotes No. 33.09\% answered Yes, 66.91\%.answered No.

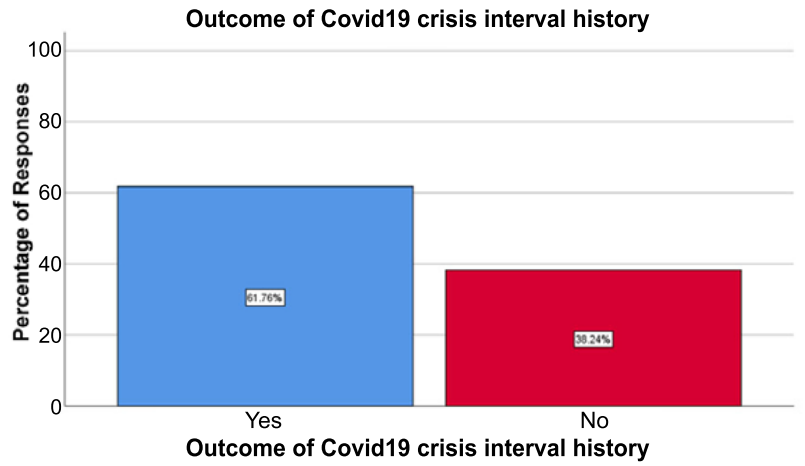

Figure 8: Bar graph representing the percentage distribution of awareness of impact of the COVID-19 outbreak affecting the travel industry. $\mathrm{X}$-axis represents the responses and $\mathrm{Y}$-axis represents the percentage of responses where Blue color denotes Yes and red color denotes No. 61.76\% answered Yes, $38.24 \%$ answered No. 


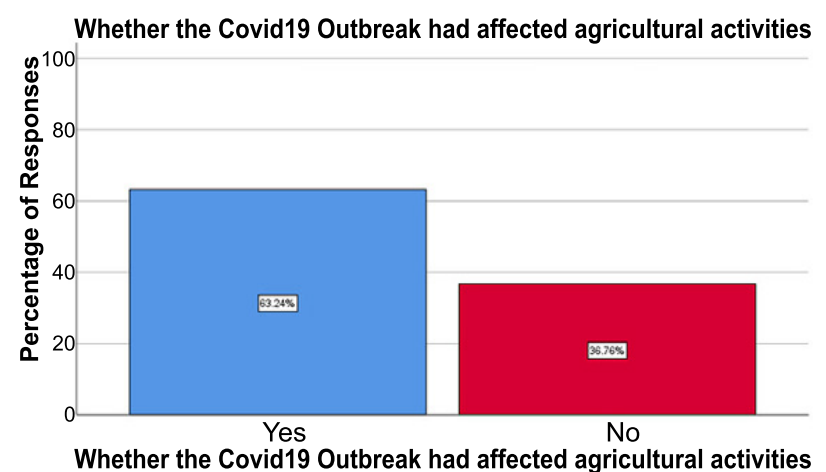

Figure 9: Bar graph representing the percentage distribution of responses to awareness of whether the COVID-19 outbreak had affected agricultural activities. $X$-axis represents the responses and $\mathrm{Y}$-axis represents the percentage of responses where Blue color denotes Yes and red color denotes No. $63.24 \%$ answered Yes, $36.76 \%$ answered No.

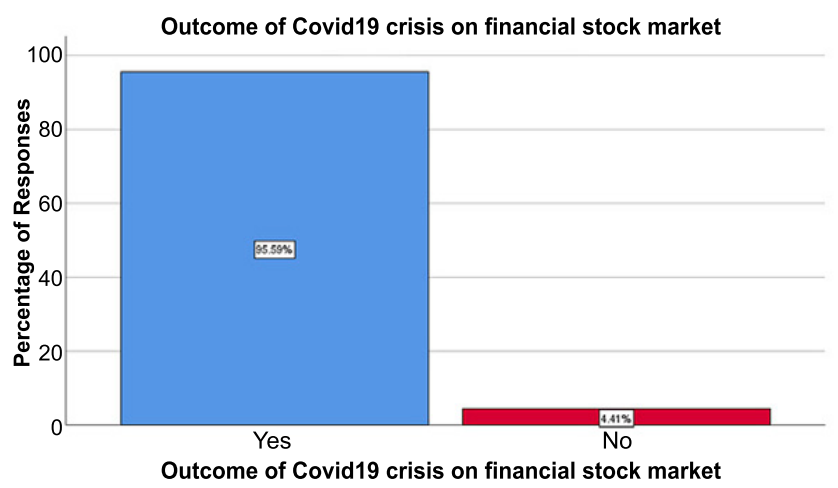

Figure 10: Bar graph representing percentage distribution of awareness on Pandemic COVID-19 impact on the stock market. X-axis represents the gender and $\mathrm{Y}$-axis represents the number of responses. Where Blue color denotes Yes and red color denotes No. $95.59 \%$ were aware of it and $4.41 \%$ were unaware.

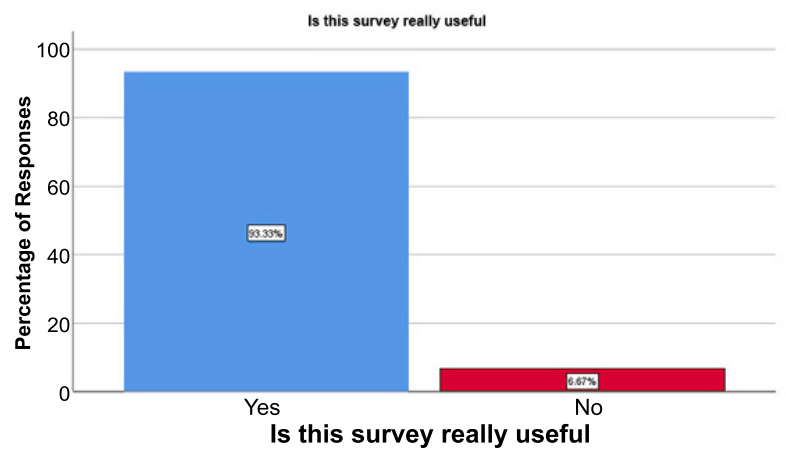

Figure 11: Bar graph representing the percentage distribution of opinions of the participants about the survey. X-axis represents the responses and $\mathrm{Y}$-axis represents the percentage of responses. Where blue color denotes Yes and red color denotes No. The majority of the respondents at 93.33 percent felt that this survey was really useful and due to this the way they gained some adequate knowledge on the impact of pandemic COVID-19 on the global economy.

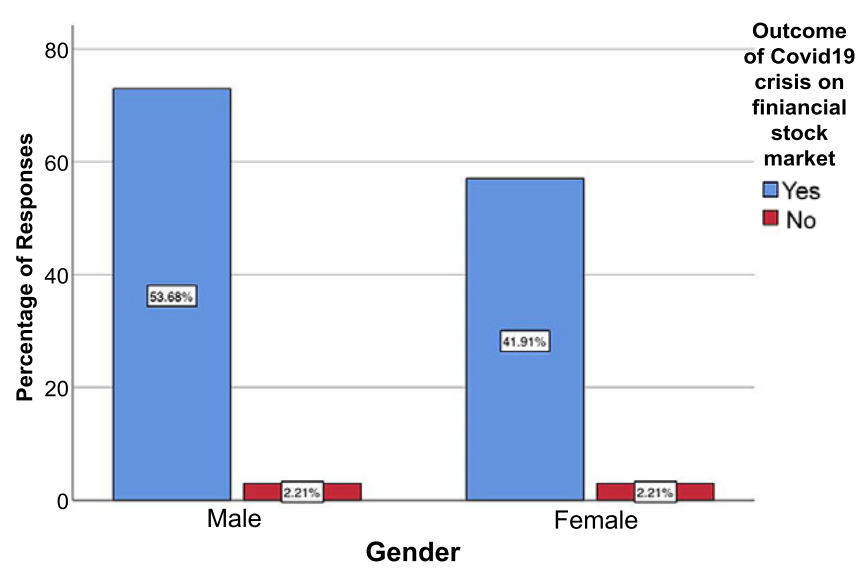

Figure 12: Bar graph representing the association between gender and awareness on the outcome of COVID-19 outbreak affecting the financial stock market. $X$-axis represents the gender and $\mathrm{Y}$-axis represents the number of participants responded where blue color denotes yes and red color denotes no. Males had better awareness than females. Pearson's Chisquare test $P$-value $-0.765(>0.05)$ - and it was not statistically significant.

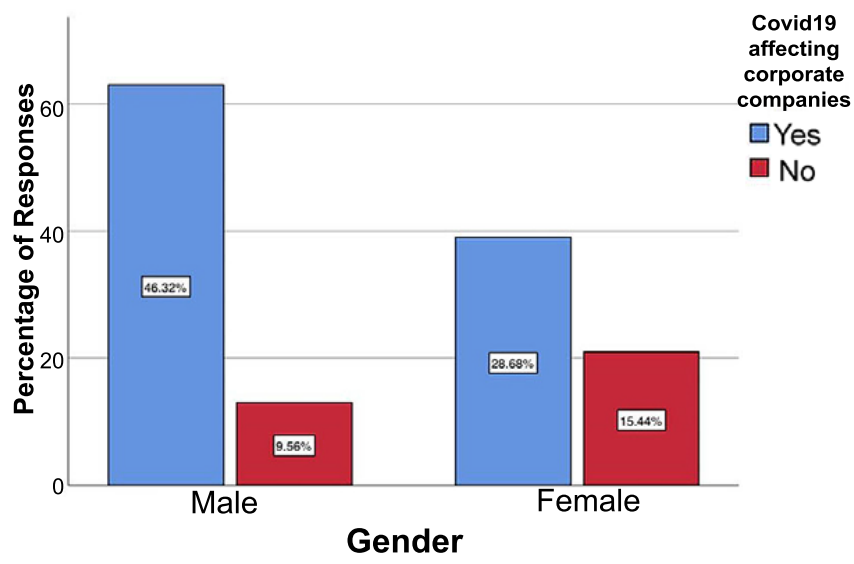

Figure 13: Bar graph representing the association between gender and awareness of the impact on COVID-19 affecting corporate companies. $\mathrm{X}$-axis represents the gender and $\mathrm{Y}$-axis represents the number of participants responded where blue color denotes yes and red color denotes no. Males had better awareness than females. Pearson's Chi-square test P-value $0.017(>0.05)$ - and it was found to be statistically significant. 


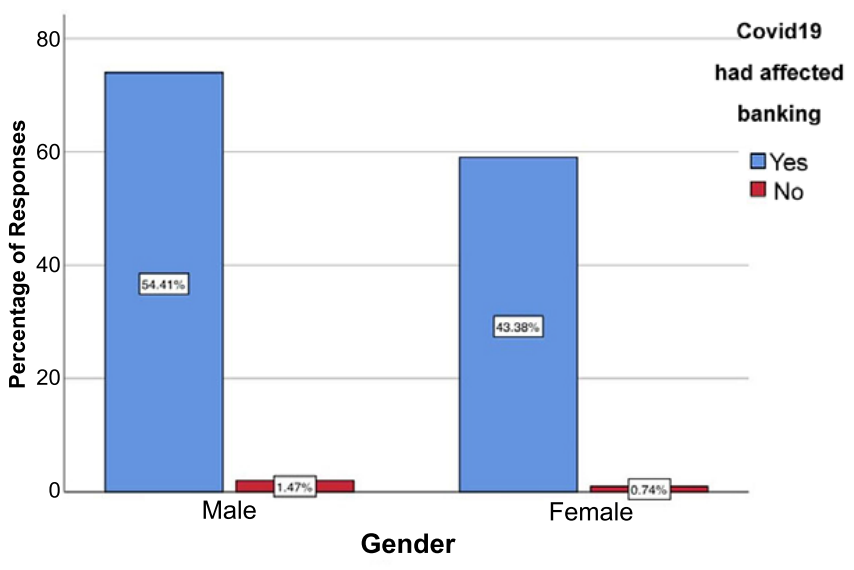

Figure 14: Bar graph representing the association between gender and awareness of COVID-19 outbreak had affected the banking sector. $\mathrm{X}$-axis represents the gender and $\mathrm{Y}$-axis represents the number of participants, where blue color denotes yes and red color denotes no. Males had better knowledge than females. Pearson's Chi-square test value - P-value - 0.704 $(>0.05)$ - and it was found to be statistically not significant.

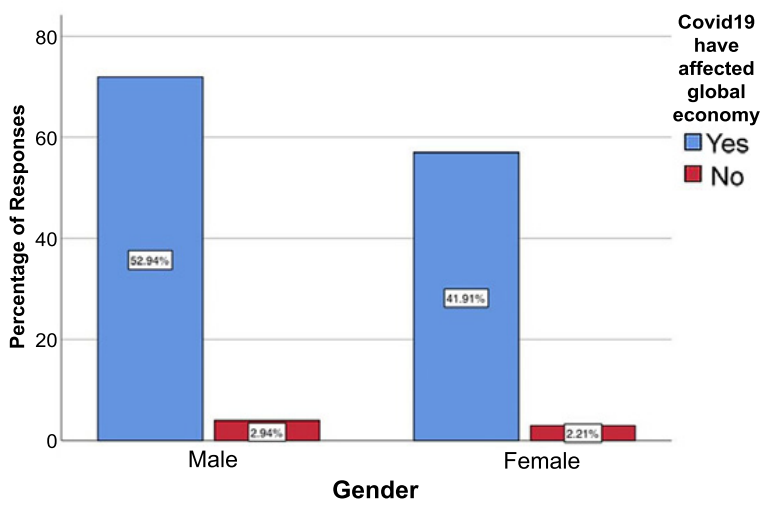

Figure 15: Bar graph representing the association between gender and knowledge of COVID-19 affecting global economy. $\mathrm{X}$-axis represents the gender and $\mathrm{Y}$-axis represents the number of participants responded where blue color denotes yes and red color denotes no. Males had better knowledge than females. Pearson's Chi-square test value P-value - 0.945(>0.05) - and it was statistically not significant. 